\title{
Portfólios: escrever em rodas de formação
}

\author{
Portfolios: writing in education teacher education \\ wheels
}

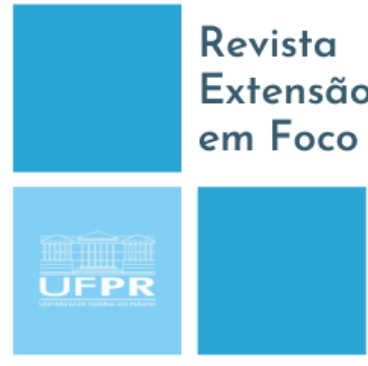

ISSN 2358.7180

\author{
Maria do Carmo Galiazzi ${ }^{1}$
}

\begin{abstract}
RESUMO
Apresento neste texto a carta que reúne as cartas escritas durante o processo de formação Cirandar 2020: rodas de investigação na escola. A carta me apresenta brevemente, conta sobre a decisão do tema a estudar e depois apresenta o texto que resultou deste estudo, produzido com duas colegas. O objetivo do estudo foi compreender os portfólios como artefatos da formação de professores. Esta intenção, por um lado, surge da minha proposição de portfólios no Programa Institucional de Bolsas da Universidade Federal do Rio Grande - PIBD/FURG, que, em todos seus editais, produziu mais de uma centena de portfólios. Por outro lado, está também sustentada na difusão que os portfólios tiveram em diferentes contextos formativos ao redor do mundo. Trago assim uma das categorias de análise resultante da pesquisa e do estudo sobre os portfólios a partir de um mapeamento bibliográfico: os portfólios de avaliação. $O$ estudo mostrou que para usar os portfólios na formação é preciso antes, estudar o conceito de avaliação para saber se este conceito sustenta a intenção pedagógica do professor.
\end{abstract}

Palavras-chave: Formação de professores. Portfólios. Avaliação.

\section{ABSTRACT}

I present in this text the letter that gathers the letters written during the Cirandar 2020 training process: rounds of investigation in the school. The letter briefly introduces me, tells about the topic's decision that I decided to study, and then presents the text that resulted from this study, produced with two colleagues. The study aimed to understand portfolios as artifacts of teacher education. On the one hand, this intention arises from my proposal for portfolios in the Institutional Scholarship Program of the Federal University of Rio Grande - PIBID / FURG, which has produced more than a hundred portfolios in all its editions. On the other hand, the portfolio diffusion in different training contexts around the world sustains my decision. So I bring one of the analysis categories resulting from the research and study on portfolios based on a bibliographic mapping: the evaluation portfolios. The study showed that to use portfolios in training, it is necessary first to study the evaluation concept to find out if this concept supports the teacher's pedagogical intention.

Keywords: Teacher education, Portfolios. Assesment.

\section{INTRODUÇÃO}

Neste texto apresento a carta cirandeira 2020 que reúne as três cartas que escrevi e que descreve o estudo que realizei ao longo do ano sobre os portfólios. Tenho estudado

\footnotetext{
${ }^{1}$ Doutora em Educação pela Pontifícia Universidade Católica do Rio Grande do Sul, Universidade Federal do Rio Grande - FURG, Rio Grande do Sul, Brasil, mariagaliazzi@ furg.br, https://orcid.org/0000-0003-0513-0018
} 
os portfolios por ter sido coordenadora institucional do Programa de Institucional de Bolsas de Iniciação à Docência - PIBID da Unviersidade Federal do Rio Grande desde sua implementação até 2017, ano de minha aposentadoria. Foram quase dez anos nesta atividade que originou uma centena de portfólios. O estudo surge de uma intenção de compreender os portfolios como artefato de formação e aqui apresento um dos textos resultantes deste estudo que está em elaboração juntamente com duas participantes do PIBID, Profa. Elaine Pereira, também coordenadora do PIBID e Profa. Liliane Antiqueira que foi bolsista do PIBID no subprojeto Matemática e que posteriomente fez pesquisa sobre a escrita naquele subprojeto.

Assim, apresento a carta cirandeira e uma síntese do texto resultante deste estudo em grupo.

\section{CARTA CIRANDEIRA 2020}

Rio Grande, 13 de março de 2021

Queridas Cirandeiras e queridos Cirandeiros!

Espero que todos vocês estejam bem de saúde e tendo coragem e ousadia para enfrentar este momento difícil que o mundo está passando. Vamos lembrar Paulo Freire e o tempo de esperançar. E o Cirandar é um tempo de esperançar enquanto vão passando dias e noites de Sol e Terra se movimentar, levando a Lua junto e neste movimento nos mostrando a necessidade de esperança. Até nisso estamos intervindo. $\mathrm{O}$ aquecimento global está aí por nossa responsabilidade. Pela educação é possível intervir. Não que seja fácil nem que dê grandes resultados, mas temos que continuar nesta luta, pois a mudança é a longo prazo!

Hoje assistindo Ailton Krenak, palestrante que encerrou o Seminário do Centenário de Paulo Freire, realizado por iniciativa de uma universidade inglesa (sic!), perguntado como ele pensava sobre educação pós-pandemia e ele falou que temos que inventar uma vacina pedagógica! Isso me leva a muitas reflexões e de como é importante como professora continuar estudando. Pelo estudo é que nos protegemos dos vírus pedagógicos! 
Para os que não me conhecem, sou professora voluntária da Universidade Federal do Rio Grande - FURG, atuando no momento especialmente nos cursos EaD, mas trabalhei na Escola de Química e Alimentos desde 1985 e na Licenciatura em Ciências desde 1989. Deste tempo todo, o que mais aprendi e insisto é que ser professor é ser coletivamente plural e o Cirandar que inventamos desde 2012 inspiradas no Encontro de Investigação na Escola e no Encontro Ibero-americo de escolas que fazem Investigação. Não tenho em toda minha história de formação, processo e experiência tão rica. Outra experiência marcante que tive foi um processo formativo durante a implantação do Ensino Médio Politécnico, que era um Cirandar específico dentro do Cirandar. Ou seja, eu faço Cirandas formativas desde há muito tempo. Na pós-graduação foi o mesmo processo com foco nas pesquisas dos mestrandos e doutorandos do PPGEA! E fiz durante 10 anos! Ou seja, eu credito muito neste formato.

Na primeira carta eu conto meu início pandêmico, mas está coloca na carta de orientação da escrita, então não vou repetir como foram múltiplas mainhas invenções até encontrar um modo extenuante de estar em Lives e em aulas à distância.

Foram importantes as Lives semanais do Cirandar, o estudo com a Ana Laura, e destes temas surgiam temas para aprofundamento: as mulheres e as bruxas, como os livros didáticos naturalizam questões socioambientais seja nos exercícios, nas imagens, em todos seus dizeres?

Bom, mas o que conto é que não foi nada disso que estudei muito. Havia esquecido de contar que às quartas pesquisava os portfólios em um projeto de pesquisa com colegas do PIBID e foi isso que estudei e que, então, mostro a seguir. Do estudo, organizei com duas colegas Profa. Liliane Antiqueira e Profa. Elaine Pereira um artigo que ainda vai ser melhorado, mas a ideia está no texto que coloco a seguir. Vocês, talvez considerem que seja um texto acadêmico e que não deveria estar aqui. Sim, mas se a intenção do Cirandar é mostrar nossos estudos, foi isso que estudei: os portfólios na formação de professores. Lá no final mando um presente a todos! Espero contribuir para quem ler problematizar a avaliação que desenvolve em sua sala de aula.

O título que dei por enquanto foi este: Mapeamento bibliográfico de pesquisas sobre portfólios de avaliação e suas metodologias: de que avaliação? Segue o texto final no próximo item. 


\section{$* * *$ \\ MAPEAMENTO BIBLIOGRÁFICO DE PESQUISA SOBRE PORTFÓLIOS DE AVALIAÇÃO E SUAS METODOLOGIAS: DE QUE AVALIAÇÃO? ${ }^{\text {i }}$}

Fui coordenadora do Programa Institucional de Bolsas de Iniciação à Docência da Universidade Federal do Rio Grande (PIBID/FURG) até 2018. Desde o primeiro edital da Coordenação de Aperfeiçoamento de Pessoal de Nível Superior (Capes), em 2009, foram produzidos mais de uma centena de portfólios coletivos em subprojetos disciplinares das Licenciaturas, em subprojetos de administração escolar e em subprojetos interdisciplinares. E a intenção deste estudo foi entender esta atividade. Inicialmente realizamos o mapeamento (BIEMBENGUT, 2008) de artigos em revistas científicas com revisão por pares. Inicialmente foi feita a identificação das produções existentes, posteriormente, sua classificação e organização. Para identificar as produções, buscaramse artigos em revistas brasileiras com QUALIS A1, A2, B1 e B2, revistas com revisão por pares em língua espanhola e em língua inglesa no Periódicos da CAPES com as palavras chave portfólio e formação de professores nos títulos dos artigos nas respectivas línguas. Resultaram 209 artigos. O processo recursivo de categorização, a partir das 262 unidades de significado oriundas dos resumos, deu origem a dezesseis (16) categorias intermediárias. Estas categorias, por aproximação de sentidos, originaram sete (07) categorias finais: "Discurso dos participantes sobre portfólios", "Portfólio como artefato institucional", "Portfólio de avaliação pelos professores", "Portfólio de reflexão dos licenciandos", "Portfólio como Rede de formação", "Olhar sobre o Portfólio em si", "Discurso teórico e bibliográfico sobre os portfólios".

Posteriormente ao mapeamento, seguiram-se os procedimentos da Análise Textual Discursiva - ATD, de Moraes e Galiazzi (2011): unitarização e categorização recursiva dos resumos destes artigos.

A Análise Textual Discursiva é uma metodologia de análise de informações textuais e discursivas com abordagem fenomenológica e hermenêutica. A inspiração fenomenológica está na Fenomenologia de Husserl (BICUDO, 2011) e a inspiração hermenêutica em Gadamer (SOUSA e GALIAZZI, 2018). A estrutura da ATD consiste nas etapas: a) fazer a leitura de cada texto, captando o sentido; b) discriminar as unidades de significado; c) delinear e reescrever as unidades em função do fenômeno em estudo; d) realizar aproximação por sentido, originando categorias para a análise; e) descrever a 
interpretar as categorias com a produção de metatextos (GALIAZZI, LIMA, RAMOS, 2020).

O portfólio do PIBID/FURG não foi pensado como documento avaliativo, mas esta foi uma caracterização Este texto discute a categoria "Portfólio de avaliação por professores" Apresentam-se a seguir a metodologia de análise do corpus e as categorias resultantes da análise.

Vou a seguir falar um pouco sobre como analisamos este conjunto de informações de 22 artigos que trataram de "Portfólios de avaliação por professores", dois artigos oriundos da busca em Espanhol, seis artigos em Português e quatorze artigos em Inglês. Os artigos originam-se, em sua maioria dos Estados Unidos (12), mas também de outros países como: Arábia Saudita (01), Argentina (01), Brasil (07); Costa Rica (01), Holanda (01), Inglaterra (01) e Noruega (02).

Com o corpus constituído, cada artigo foi lido integralmente e elaborada uma síntese descritiva considerando a intencionalidade do estudo sintetizada na pergunta: $\mathrm{O}$ que é isso que se mostra em artigos científicos sobre o uso de portfólios como artefato de avaliação na formação de professores? A correspondência entre a síntese descritiva e o artigo original ocorreu por uma leitura comparativa entre os dois documentos. Deste processo, emergiram duas inquietações. Os artigos tratavam de pesquisas e ensaios sobre o uso dos portfólios para avaliação dos estudantes, mas de que avaliação tratava? Nos títulos dos textos algumas palavras mostraram diferenças como: avaliação formativa, avaliação somativa, auto-avaliação e autorregulação. O que significava para os autores dos estudos cada uma destas palavras? A outra inquietação foi relativa à explicitação dos modos de pesquisa e de análise realizados, pois em alguns destes artigos estas informações não estavam claras. Estas inquietações orientaram a análise.

Também da análise ficou claro que os portfólios têm sido utilizados em diferentes níveis de ensino e segmentos educacionais: cursos experimentais (2), cursos de formação de professores em geral (8), Pedagogia (3), Inglês, (3), Música (1), Formação em serviço (1), Educação Básica (1), Ensino Médio (1).

Com relação ao tipo de trabalho, observou-se que foram: ensaios (2), relatos de experiência (4), pesquisas qualitativas (3) pesquisas quantitativas (5), pesquisa-ação (1), estudo de caso quantitativo (1), estudos de caso qualitativo (2), pesquisa qualiquantitativa (1), revisão bibliográfica (1), pesquisa narrativa (1). 
A compreensão sobre avaliação dos pesquisadores assim se mostrou nos artigos: não consta no artigo a conceituação de avaliação (14); apresentaram características da avaliação formativa (2), apresentaram conceituação da avaliação formativa (4), avaliação construtivista (1), avaliação montessoriana (1), autoavaliação (1).

Percebemos também que nos textos mais antigos e na maioria dos textos publicados em Inglês não há referência a algum aporte teórico que fundamente o conceito de avaliação. Da leitura e produção das sínteses descritivas dos 22 textos, 11 não apresentaram esta conceituação, sendo três relatos de experiência e oito pesquisas quantitativas com número elevado de participantes e de portfólios analisados. Muitos pesquisadores quantitativos tem se dedicado à avaliação somativa dos portfólios nos Estados Unidos. pois, de acordo com Beck, Nava e Bear (2005), um levantamento mostrou que $90 \%$ das universidades americanas usavam os portfólios para alguma etapa de classificação de seus estudantes e $40 \%$ usavam como requisito para fornecer a certificação final e a complexidade da avaliação estava muito presente no contexto americano. No conjunto de textos, há, no entanto, pesquisas quantitativas sobre a avaliação somativa mais recentes em outros países.

Considerando a intencionalidade de compreensão, seguimos com a análise com os textos que apresentaram, mesmo que rapidamente, alguma fundamentação teórica sobre a avaliação e descrevemos cada trabalho, mas como é extensor não vou detalhar o que fizemos, mas em síntese, os artigos apresentaram muitos argumentos favoráveis ao uso de portfólios de avaliação, no entanto, diverge em parte o posicionamento apresentado por Tinoco (2012). O trabalho emergiu de uma inquietação oriunda de relatos de professores e alunos sobre seus portfólios. A autora se perguntou: O que são portfólios? Como eles vêm sendo apropriados pelos professores nos diversos níveis de ensino? Como se avalia por meio desse instrumento? Esses questionamentos foram realizados a professores em diferentes turmas de formação continuada. Com base principalmente em Fernando Hernandez (2000) o texto foi construído apresentando o portfólio como um instrumento que possibilita constante reflexão, sendo que aluno e professor poderão visualizar os documentos tendo em mente os objetivos e os critérios anteriormente acordados, dialogando com as soluções e os problemas que forem surgindo, a partir das tarefas solicitadas. O objetivo do artigo foi contribuir para a compreensão desse instrumento de avaliação, mas sobre o qual as práticas apresentam certa incoerência. Apresentando o conceito, os elementos que compõem um portfólio e a forma de avaliá- 
lo, o artigo apresenta subsídios para a melhor utilização desse instrumento por professores e alunos nos diversos níveis de ensino.

Este foi um dos poucos textos que apresentou explicitamente a compreensão de avaliação da autora e é interessante que foi este aspecto que mostrou o fenômeno (a categoria analisada em item posterior) emergente. Em trabalhos descritos anteriormente sobre portfólios na Educação Infantil, uma inquietude também esteve acompanhando a leitura do corpus. Seria adequado fazer portfólios na Educação Infantil? A autora considera que não é adequado e isso, de certa forma, amenizou esta inquietude.

Questionamos em um estudo anterior a pluralidade de objetivos para um mesmo portfolio (ANTIQUEIRA, PEREIRA, GALIAZZI, em avaliação) e Tinoco (idem) fortaleceu este argumento. Um objetivo já é suficiente e desafiador em um portfólio. Também este foi um dos poucos textos que abordou os portfólios coletivos. A reflexão sobre a justificativa para a escolha de um e outro documento também é imprescindível, segundo a autora. No entanto, para uma correta interpretação dos modos de se trabalhar com o portfólio, o investimento em formação continuada precisaria ser contínuo para que a educação não fique à mercê de interpretações superficiais. Seria por meio da formação continuada que cada professor poderia, por sua vontade e persistência (sic!), se transformar em pesquisador, com uma forte base conceitual, capaz de mudar, inclusive, sua postura política. A partir do exposto, reafirmamos a necessidade de valorização docente com condições adequadas de trabalho para que o professor persista em sua formação. Neste sentido, coletivos de professores seriam importantes.

E nos perguntamos sobre a avaliação formativa e trago parte do estudo também para não me alongar. A avaliação somativa está impregnada na lida professional. A origem da expressão avaliação formativa tem sido apontada repetidamente por vários autores (PINTO ROCHA, 2011; VILLAS BOAS, 2004) a partir de um artigo de Scriven (1967). A história do conceito foi detalhada por Pinto e Rocha (2011\0 e uma arqueologia do conceito foi realizada por Gama (2004).

Harlen e James (1997) assinalaram que a avaliação formativa é aquela conduzida pelo professor para promover a aprendizagem. Esta avaliação considera o desenvolvimento do aluno e o que na avaliação somativa é considerado erro, na avaliação formativa aponta como possibilidade de intervenção de modo a promover a aprendizagem. 
Para Villas Boas (2004), o que diferencia a avaliação somativa da avaliação formativa são seus objetivos que são distintos. A avaliação formativa não tem como foco apenas o professor. Ela integra também na avaliação, o professor e a escola. Nas palavras da autora:

A avaliação formativa é a que usa todas as informações disponíveis sobre o aluno para assegurar sua aprendizagem. A interação entre professor e aluno durante todo um período ou curso é um processo muito rico, oferecendo oportunidade para que obtenham vários dados. Cabe ao professor estar atento para identificá-los, registrá-los e usá-los em benefício da aprendizagem. (Villas Boas, 2004, p. 36).

Os artigos estudados fizeram destaques a alguns aspectos da avaliação e deles extraíram-se conceituações e características. Villas Boas (2005) assinalou que na formação de professores o estudo sobre a avaliação tem recebido pouca atenção e isso exige uma mudança em que o professor e os estudantes atuem em parceria e isso exige mais do que atribuir notas em testes e exames. Para isso, é preciso autonomia intelectual e condições de trabalho adequadas. E o portfólio é um artefato que propicia a avaliação formativa, pois permite avaliar o pensamento crítico por meio de seus registros, de apresentar, articular e poder encaminhar soluções para problemas complexos, bem como intensificar o trabalho colaborativo, o registro de projetos em que o estudante pode ter seus próprios objetivos de aprendizagem.

Alvarenga e Araújo (2006) argumentam sobre a necessidade de uma formação efetiva sobre a avaliação que precisa ser um compromisso com o ensino e com a aprendizagem por isso apostam em cursos de extensão.

Da sala de aula de Banfi (2003) extrai-se a importância do feedback, processo exigente e continuado. $\mathrm{O}$ feedback é elemento inextricável de uma avaliação formativa de sala de aula (VILLAS BOAS, 2019).

Ao questionar se o portfólio não é somente mais um modismo na educação de Tinoco (2012) apresenta claramente o entendimento de avaliação como processo investigativo dos processos de ensino e de aprendizagem. Com esta concepção, a avaliação inclui reflexão, compromisso e ação para que o professor possa redefinir os rumos de sua prática educacional (p. 460). E esta modalidade de avaliação é denominada de avaliação formativa (ALVES, 2004; BOUGHTON, 2005; EARL, RYAN, 2001; ESTEBAN, 2003; GERALDI, 2003, HARGREAVES; HADJI, 2001; HERNÁNDEZ, 
2000; PARO, 2001, PERRENOUD, 1999; VASCONCELLOS, 2003; ZIMMERMAN, 2005).

Para Oliveira e Elliot (2012), ao propor o portfólio para avaliação do processo de ensino e de aprendizagem 2, a avaliação é um processo aberto para promover a aprendizagem. O aporte teórico para esta compreensão foi Villas Boas (2004) que defende que a principal função da avaliação é ajudar a aprendizagem, compreensão obviamente muito diferente do que normalmente ainda se apresenta como instrumento de classificação e aprovação.

O estudo monográfico apresentado por Raposo e Silva (2012) reforça a importância da avaliação ser um processo investigativo com discussão, argumentação, contra-argumentação, numa reflexão conjunta. Na mesma direção, as autoras se fundamentam em Vasconcellos (1994) que apresenta cinco princípios para uma avaliação formativa que são: a) alterar a metodologia em sala de aula; b) diminuir a avaliação classificatória; c) redimensionar o conteúdo da avaliação; d) alterar a postura diante dos resultados e e) esclarecer a comunidade educativa.

A compreensão de avaliação que se compreende de Nascimento e Rôças (2015) é que segundo a concepção construtivista da avaliação deve ser dialógica, mediadora, formativa e integrada aos processos de ensino e de aprendizagem (p. 757). Esta compreensão sustenta-se em Hadji (2001), Luckesi (2002), Hoffmann (2001 e 2011).

Da análise realizada neste estudo, pode-se sintetizar: nem sempre os autores que assumem o portfólio como artefato de avaliação expressaram com clareza o conceito de avaliação, ou mesmo como se mostrou, não foi preocupação dos autores expressar suas compreensões. Alguns autores apenas usaram a expressão avaliação formativa sem a conceituar, outros apresentaram abordagens distintas como avaliação construtivista e avaliação montessoriana, outros, características próximas da avaliação formativa. Ou seja, embora o conceito de avaliação formativa tenha sido o mais citado, obviamente não é o único.

Em uma revisão bibliográfica sobre o conceito de avaliação formativa, Pinto e Rocha (2011) assinalaram algumas tendências: a) os estudos que mencionam elementos

\footnotetext{
${ }^{2}$ As autoras usam a expressão processo de ensino-aprendizagem. Usa-se a expressão processos de ensino e de aprendizagem, pois entende-se que não seja um único processo, embora se concorde com sua relação intrínseca.
} 
que devem compor uma avaliação formativa sem a conceituar; b) a baixa frequência de termos como emancipação o que acentuam marcas conservadores à avaliação e c) a baixa frequência com que são mencionadas os sistemas escolar, social, político e econômico (p. 573), o que de certa forma se aproxima com os resultados encontrados agora.

Segundo Pinto e Rocha (2011), os deslocamentos conceituais são até justificados teoricamente, no entanto é preciso que estes deslocamentos sejam feitos a partir de aportes teóricos e por isso seriam necessárias discussões e esforços para tornar mais profundo o entendimento sobre avaliação formativa porque o conceito não é único e não basta informar rapidamente que se assumiu uma perspectiva de avaliação formativa.

Na revisão bibliográfica sobre avaliação formativa de 1999 a 2009, Pinto e Rocha (2011) extraíram da análise de 20 textos que abordaram a avaliação da aprendizagem, características da avaliação em uma lógica formativa. Foram elas:

processo contínuo e progressivo; atividade flexível do processo de
ensino e de aprendizagem, supervisão e acompanhamento do
aprendizado dos alunos; orientadora da atividade educativa;
individualizada promovendo o desenvolvimento de cada indivíduo,
prática educativa contextualizada; práticas avaliativas integradoras e
não excludentes; práticas de avaliação fundamentadas no diálogo;
finalidade a reflexão sobre a prática tanto do professor como do aluno;
autoavaliação para tomar consciência do processo de aprendizagem;
fornecer feedback; intervenção no processo de aprendizagem e
instrumentos e elementos de avaliação devem ser diversificados
(PINTO; ROCHA, 2011, p. 571)

Estas características foram sintetizadas da revisão bibliográfica citada, no entanto as mais comuns foram a importância de ser um processo contínuo e progressivo que seja orientador da atividade pedagógica e favorável à autoavaliação para que o aluno possa tomar consciência de seu processo de aprendizagem.

Nesta revisão bibliográfica, as autoras destacaram o texto de Gama (2004) por problematizar o conceito de avaliação formativa a partir de teóricos bastante referenciados como Hadji (20011), Afonso (2000) e Perrenoud (1999). Segundo Gama (2004) é preciso cautela ao assumir a avaliação formativa, estando atentos mais a eficácia, competitividade, excelência e gestão, diminuindo a autonomia dos professores. Villas Boas (2019) afirma que o portfólio é o artefato adequado para uma avaliação formativa. Gama (2004) com uma compreensão de currículo a partir das teorias pós-críticas, o conceito de avaliação formativa não apresenta alternativas nessas teorias. 
Com os mesmos argumentos apresentados por Gama (2004) se poderia problematizar também a avaliação emancipatória proposta por Saul (1985), que desde que foi proposta teve diferenças em suas acepções, o que aponta para uma provável dispersão como analisado por Gama (2004) rferente à avaliação formativa. No entanto, reconhecendo a importância do pensamento de Freire em que se assenta a avaliação emancipatória uma compreensão de avaliação poderia também fundamentar o trabalho com portfólios de avaliação.

Chama atenção especialmente o compromisso com a transformação social que transcende o compromisso com a aprendizagem. Ou seja, outra possibilidade de trabalho e de avaliação para os portfólios.

Assim, ressalta-se o cuidado para, ao propor os portfólios de avaliação como alternativa, não cair em armadilhas inculcadas nos modos de avaliar que podem reafirmar uma avaliação excludente, classificadora e certificadora. E para não cair em armadilhas é preciso estudo e para poder estudar é preciso financiamento, políticas públicas, diálogo.

Pretendeu-se neste texto fazer o exercício hermenêutico partindo da expressão avaliação nos textos que pesquisaram os portfólios de avaliação. Foram apresentadas as sínteses descritivas dos textos que, de certa forma, apresentaram suas compreensões e conceituações de avaliação. Destacaram-se estas compreensões, mostrando que é um conceito complexo e diverso em sua aplicação. Mostrou-se interlocução teórica no movimento em direção ao conceito e com maior compreensão dele se retorna à expressão para concluir com algumas considerações.

Depois de todo este estudo fizemos algumas considerações:

O que se mostrou neste texto foi apenas uma sistematização sobre a pesquisa sobre o uso dos portfólios de avaliação na formação de professores considerando principalmente as impressões que seu uso provocou nos envolvidos em sua produção e avaliação. Conhecer sobre os modos de pesquisa e identificar a fundamentação teórica que sustentou estas pesquisas em relação à avaliação pode ajudar a compreender o uso dos portfólios na formação docente em que este artigo é uma das categorias de análise e como pesquisá-los.

Extrai-se do que foi aqui apresentado que, ao assumir os portfólios de avaliação, é preciso esclarecer e em que pressupostos se assenta a decisão pedagógica pelo 
desenvolvimento deste artefato. E isso precisa estar claro tanto para o proponente quanto para os demais envolvidos, o que exige diálogo. Os portfólios na formação de professores se inserem em movimentos que buscam problematizar modos conservadores de ensino. Mexer nestes processos e especialmente na avaliação é um processo lento e continuado em que é mister buscar por aportes teóricos que sustentem e dêem clareza a decisão.

O conceito de avaliação é um conceito complexo com diferentes acepções que sustentam modos de entender a avaliação distintos. Estes aportes teóricos têm uma densa construção teórica que precisam ser aprofundados, discutidos, problematizados.

Um segundo aspecto que sobressai nesta análise é que as informações empíricas foram obtidas preponderantemente pelas pessoas, estudantes, comunidade escolar, responsáveis pelas crianças e avaliadores e menos dos registros nos próprios portfólios. Entende-se que nestes procedimentos de pesquisa estão presentes relações de poder que merecem atenção. Analisar os portfólios em si pode trazer informações genuínas sobre o potencial dos portfólios para a aprendizagem na formação de professores. Esta é a intencionalidade colocada no projeto de pesquisa do qual este estudo fez parte.

Por último é muito importante para o uso de portfólios de avaliação na formação de professores a valorização da profissão docente com condições adequadas de trabalho para que essas discussões possam ocorrer em diferentes instituições educativas com aprofundamento conceitual inextricável à prática docente. Isso exige investimento público porque educação é uma questão pública.

Claro que de todo este estudo temos que indicar as referências analisadas e estudadas, mesmo sendo uma carta e são as que seguem.

\section{REFERÊNCIAS}

ALSHAWI, Arrej T.; ALSHUMAIMERI, Yousif A. Teacher Electronic Portfolio and its Relation to EFL Student Teacher Performance and Attitude. International Journal of Education \& Literacy Studies. v. 5, n. 1, Jan. 2017.

ALVARENGA, Georfravia; ARAUJO, Zilda; Portfólio: conceitos básicos e indicações para utilização. Est. Aval. Educ., 2006, Vol. 17(33), p. 137-147.

BANFI, Cristina. Portfolios: integrating advanced language, academic and professional skills. ELT Journal. vol. 57/1, Jan. 2003. Accessed 19 Dec. 2020. 
BECK, Robert J.; NAVA, Livne L.; BEAR, Sharon L. Teachers, self-assessment of the effects on formative and summative electronic portfolios on professional development. European Journal of Teacher Education, v. 28, n. 3, October 2005, p. 221-244.

BIEMBENGUT, Maria Salett. Mapeamento na pesquisa educacional. Rio de Janeiro: Ciência Moderna, 2008, 135 p.

DENNEY, Maria K.; GRIER, Jeanne M.; BUCHANAN, Merylin. Establishing a portfolio assessment framework for pre-service teachers: a multiple perspectives approach. Teacher in Higher Education. v. 17, n. 4, p. 425-437

GALIAZZI, Maria do Carmo; LIMA, Valderez R.; RAMOS, Maurivan G. A fusão de horizontes na Análise Textual Discursiva. Revista de Pesquisa Qualitativa, 2020, v.8, n.20, p. 610-640.

GALIAZZI, Maria do Carmo; SOUSA, Robson Simplício de. Atos de Pesquisa em Educação. 2019, Atos de Pesquisa em Educação, v. 15, n. 4, p. 1167-1184.

GAMA, Zacarias Jaegger. Avaliação Formativa: ensaio de uma arqueologia. Est. Aval. Educ. n. 29, jan/sun. 2004.

GRACIA, Raul W. C. El portafolio electrónico como instrumento de evaluación y como estrategia de autorregulación en la formación de profesionales en música. Revista Educación. 2018, v. 42, n. 2, p. 2215-2644

GEIGER, John; SHUGARMAN, Sherrie. Portfolios and case studies to evaluate teacher education students and programs. Action in Teacher Education, 1988, 10:3, 3134.

GELFER, Jeffery; PERKINS, Peggy G. A Model for Portfolio Assessment in Early Childhood Education Programs. Early Childhood Education Journal, 1996, vol. 24, n. 1p. $5-10$.

HAUGE, Trond Elliv. Portfolios and ICT as means of professional learning in teacher education. Studies in Education Evaluation, 200, n. 32, p. 23-36

LOMBARDI, Judy. To Portfolio or Not to Portfolio: Helpful or Hyped? College Teaching, 2008, Vol.56(1), p.7-10. 
MILLS, Lynne. Educating Undergraduate Education Majors in the Use of Portfolio Assessment for Preschoolers, Journal of Early Childhood Teacher Education, 1006, vol 17:2, 32-38.

MORAES, Roque; GALIAZZI, Maria do Carmo, Análise Textual Discursiva, 3. ed. Unijuí, 2016.

NASCIMENTO, Lucilene Aparecida E Lima do; RÔÇAS, Giselle. Portfólio: uma opção de avaliação integrada para o ensino de Ciências. Est. Aval. Educ. São Paulo, v. 26, n. 63, p. 742-767, set./dez., 2015.

NASCIMENTO, Anelise Monteiro; BARBOSA, Silvia Néli Falcão. Educa Revista Multidisciplinar em Educação, Porto Velho, v.6, n. 16, p. 27-48, out./dez., 2019

OLIVEIRA, Delcy Lacerda de; ELLIOT, Lígia Gomes. O portfólio como Instrumento de Avaliação da Aprendizagem na Escola Montessoriana. Meta: Avaliação, v. 4, n. 10, 2012.

PINTO, R. O; ROCHA, M. S. P. M. L. A avaliação formativa: reflexões sobre o conceito no periodo de 1999 a 2009. Est. Aval. Educ., São Paulo, v. 22, n. 50, p. 553 576, set./dez. 2011

RAPOSO, Mirian Barbosa Tavares; SILVA, Marilda Lemos. Avaliação no Ensino Médio: o portfólio como proposta. Cadernos de Educação, Pelotas, v. 42, p. 259-281, mai a ago, 2012.

SAUL, Ana Maria. Referenciais freireanos para a prática da avaliação. Revista de Educação. PUC-Campinas, n. 25, p. 17-24, nov. 2008.

SHEPERD, Craig E.; HANNAFIN, Michael J. Examining preservice teacher inquiry through vídeo-based, formative e-portfólios. Journal of Computing in Teacher Education. v. 25, n. 1, 2008 publicado online Fev. 2014.

SHULMAN, L.S., HAERTEL, E., BIRD, T. Toward alternative assessments of teaching: a repost or work in progress. Unpublished manuscript, Stanford University, School of Education, Teacher Assessment Project, 1988. 
SMITH K.; TILLEMA, H. Use of criteria in assessing Teaching portfolios: judgemental practices in summative evaluation. Scandinavian Journal of Educational Research. v.51, n. 1, February 2007, p. 103-117.

SOUSA, Robson S. ; GALIAZZI, Maria do Carmo. O jogo da compreensão na análise textual discursiva em pesquisas na educação em ciências: revisitando quebracabeças e mosaicos. Ciência \& Educação (Bauru) v. 24, n. 3, p. 799-814.

TINOCO, Eliane de Fátima Vieira. Portfólios: mais um modismo na Educação? Revista Eletrônica de Educação. São Carlos, v. 6, n. 2, 2012.

VILLAS BOAS, Benigna Maria de Freitas. O portfólio no curso de Pedagogia: ampliando o diálogo entre professor e aluno. Educ. Soc., Campinas, vol. 26, n. 90, p. 291-306, Jan./Abr. 2005

VILLAS BOAS, Benigna Maria de Freitas Conversas sobre avaliação. Campinas: Papirus, 2019.

VILLAS BOAS, Benigna Maria de Freitas. Esmiuçando a avaliação formativa In: VILLAS BOAS, Benigna Maria de Freitas. Conversas sobre avaliação. Campinas: Papirus, 2019.

WANG, Shuyan; TURNER, Sandra. Learning experiences in developing eletronic portfolios, International Journal of Information and Communication Technology Education, v. 2, n. 3, p. 75-86, Jul/Sept2006.

YAO, Yuankun Thomas, MATT; Nickens, Joyce A. D; BURKETT, Ruth S.; LAMSON, Sharon. Validity evidence of an electronic portfólio for preservice teachers. Educational Measurement: Issues and Practice. Spring 2008.

ZUBIZARRETA, John. Teaching portfolios and the beginning teacher. Phi Delta Kappan, v. 76, n. 4, Dec. 1994, p. 323 +. Gale Academic OneFile, https://linkgale.ez40.periodicos.capes.gov.br/apps/doc/A16527522/AONE?u=capes\&sid=AONE\& xid=d25a1e55. Accessed 12 Jun. 2020

Recebido em: 15 de abril de 2021. Aceito em: 12 de maio de 2021. 
'Este texto é parte do estudo realizado pelas colegas Profa. Liliane Antiqueira e Profa. Elaine Pereira. Elaboramos o meta-texto do qual fiz uma síntese para colocá-lo na carta-cirandeira 2020. 